\title{
Anesthetic management in patients suspected of Creutzfeldt-Jakob disease
}

\section{-A case report-}

\author{
Chi Bum In, Young Sil Choi, Eun Young Park, Dong Jin Chang, Soo Kyung Lee, Hyun Choi, and \\ Hyun Soo Moon
}

Department of Anesthesiology and Pain Medicine, Hallym University College of Medicine, Anyang, Korea

Creutzfeldt-Jakob disease (CJD) is a fatal neurodegenerative disorder in which accumulation of the pathogenic prion protein induces neuronal damage and results in distinct pathologic features. This abnormal prion is an infectious protein and resistant to methods of sterilization currently being used. Therefore, management of definite, or suspected CJD patients requires additional precautions. We report our experience of a patient who had undergone brain biopsy for suspected of CJD. The patient was confirmed to have sporadic CJD. (Korean J Anesthesiol 2011; 61: 262-264)

Key Words: Anesthesia, Creutzfeldt-Jakob disease.

Creutzfeldt-Jakob disease (CJD) is a lethal form of dementia that causes progressive degeneration of the brain which in turn leads to death. It has a worldwide reported annual incidence of 1 per million [1]. CJD is classified as a form of transmissible spongiform encephalopathy (TSE) and the human forms of TSE are very rare. CJD is the most common form of human TSE. Major clinical problems are due to the small prions that enable them to reside in the microscopic crypt on instruments [2] and are resistant to all methods of sterilization currently in use, including autoclaving $\left(121^{\circ} \mathrm{C}\right.$ for $\left.15 \mathrm{~min}\right)$, high-dose ionizing radiation, and ultraviolet radiation [3]. CJD therefore has greatly increased the risk of potential cross-infection by surgical and anesthetic equipments.
We report our anesthetic experience in a patient with CJD and discuss the anesthetic and surgical precautions of a patient with definite or probable CJD.

\section{Case Report}

A 64-year-old, $164 \mathrm{~cm}, 70 \mathrm{~kg}$ woman had a five-year history of hypertension and diabetes mellitus. She experienced insomnia, nausea, visual hallucination and left-side tingling sensation 4 months ago and memory impairment and gait disturbance became evident clinically 2 months ago. At that time, she underwent brain magnetic resonance imaging, which did not demonstrate abnormality. The patient presented with

Received: December 6, 2010. Revised: 1st, February 28, 2011; 2nd, March 4, 2011. Accepted: March 7, 2011.

Corresponding author: Soo Kyung Lee, M.D., Department of Anesthesiology and Pain Medicine, Hallym University Sacred Heart Hospital, 896, Pyengchon-dong, Dongan-gu, Anyang 431-070, Korea. Tel: 82-31-380-3945, Fax: 82-31-385-3244, E-mail: agnetask@yahoo.co.kr

(c) This is an open-access article distributed under the terms of the Creative Commons Attribution Non-Commercial License (http:// creativecommons.org/licenses/by-nc/3.0/), which permits unrestricted non-commercial use, distribution, and reproduction in any medium, provided the original work is properly cited. 
generalized myoclonus, progressive gait disturbance, and deviation of the left eye 1 month ago. Clinically, her condition resembled that of terminal vegetative state. Brain MRI showed T2 hyperintensity of the right dominant cortex, caudate nucleus, putamen, and thalamus on diffusion-weighted sequences. Electroencephalogram showed nearly continuous high voltage $1-1.5 \mathrm{~Hz}$ periodic sharp waves in the frontal area bilaterally. Under the suspicion of CJD the patient was admitted for brain biopsy.

The patient was scheduled last on the operating list. The operating room was cleared of unnecessary equipment and the wall of operating room was covered with vinyl chloride monomers. All staff members involved with the operation wore liquid-repellent gown, face-masks with plastic transparent shield visor, and double gloves (Fig. 1).

The mental status of the patient ranged from stupor to semicoma and vital signs were stable. Standard monitoring were applied before induction of anesthesia. Anesthesia was induced with a bolus injection of propofol $1.5 \mathrm{mg} / \mathrm{kg}$ in combination with remifentanil infusion at $0.5 \mu \mathrm{g} / \mathrm{kg} / \mathrm{min}$. Endotracheal intubation was facilitated by vecuronium $6 \mathrm{mg}$. Anesthesia was maintained with oxygen $5 \mathrm{~L} / \mathrm{min}$, propofol $50-$ $150 \mu \mathrm{g} / \mathrm{kg} / \mathrm{min}$, and remifentanil $0.05-0.1 \mu \mathrm{g} / \mathrm{kg} / \mathrm{min}$ total intravenous anesthesia. Almost every equipment applied was of single-use nature, including face-masks, oropharyngeal airway, laryngoscopic blade, endotracheal tube, Ambu bag, $\mathrm{O}_{2}$ flowmeter, and stethoscope. The surgeon used handdrill instead of air-drill, and the entire surgical procedure took 40 minutes. Extubation was performed following in the

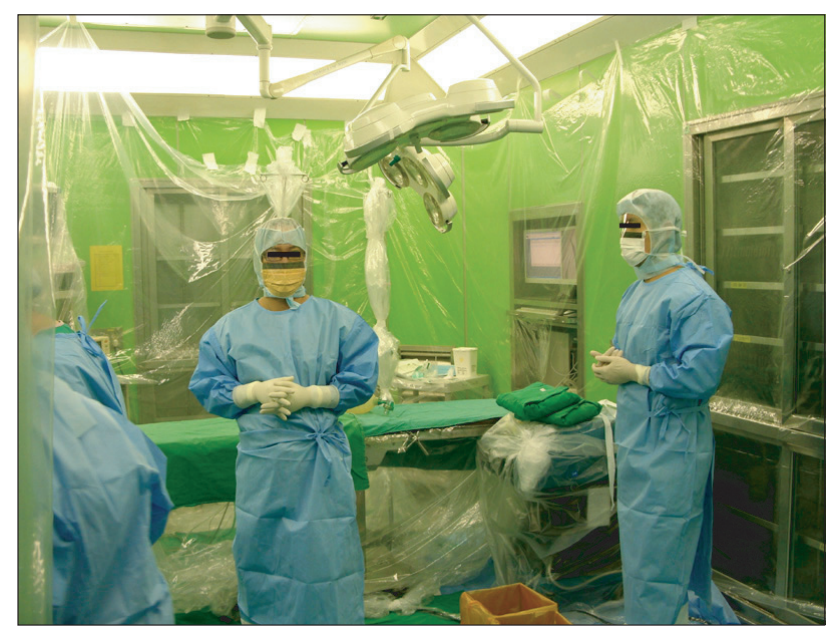

Fig. 1. For the anesthetic and surgical management of the patients suspected of Creutzfeldt-Jakob disease, the operating room is cleared of unnecessary equipment and the wall of operating room is covered with vinyl chloride monomers. All the staff entering the operation wear liquid-repellent gown, face masks with plastic transparent shield visor, and double gloves. operating room after gaining of spontaneous ventilation. The patient recovered in the operating room and was subsequently transferred to the private ward. All disposable equipment was destroyed and incinerated postoperatively.

Brain biopsy revealed neuronal loss, vaculoation, and astrocytosis in the brain tissue. Western blot demonstrated a misfolded, protease-resistant, pathogenic form of prion protein in the brain tissue. A diagnosis of sporadic CJD was made based on the above findings.

\section{Discussion}

CJD is a fatal degenerative disease of the central nervous system. It is one of the transmissible subacute spongiform encephalopathies. CJD is caused by infectious protein "prion". Prion proteins are normal cellular proteins that have undergone a structural change rendering the abnormal protein resistant to degradation [4]. Sporadic CJD (sCJD) is the most common form and accounts for $85 \%$ of cases. It is a rapidly progressing illness with an onset of older age group and a median duration of four months. Iatrogenic CJD (iCJD) accounts for fewer than $5 \%$ of cases. It is resulted from various types of therapeutic interventions including contaminated surgical equipment, corneal or dural transplants, or treatment with human-derived pituitary growth hormone [5]. In 1974, the first case of iCJD was reported in a 55-year-old woman whose symptoms began 18 months after corneal transplant surgery [6]. We had an experience a case of iCJD in a 53-year-old woman whose symptoms began 23 years after brain tumor resection and dura mater grafting. In addition, deaths from CJD have been reported in neurosurgeon and pathologist $[7,8]$. In iatrogenic transmission, various latencies, from several months to several decades, have been reported. Variant CJD (vCJD) affects mainly young individuals with an average age of 29 years, and the median duration of illness is 14 months. A new aggressive human form, known as vCJD, was first descrided in the UK in 1996 [9].

Classification of CJD should be made between symptomatic and asymptomatic patients. Symptomatic patients are divided into those who have definite, probable or possible CJD, or vCJD [10]. Asymptomatic patients are those with no clinical symptoms, but are at risk of disease development due to family history or medical history (e.g. a history of previous dural graft). Definite diagnosis of CJD requires pathological confirmation, either at autopsy or from brain biopsy [4]. The histopathological background is spongy degeneration of the grey matter [1].

CJD is rare but due to their unusual resistance to standard decontamination methods and the consequent risk of patientpatient transmission, management of the infected and, possibly infected patients requires additional precautions. In the most routine clinical contacts no additional precautions are 
required and isolation nursing is unnecessary. However, in the operationg room, controls are required to prevent iatrogenic transmission [10].

When a patient known to have, or suspected of having CJD is scheduled for anesthesia, special precaution is required thorough the procedure. The anesthesiologist should confirm the level of certainty of the diagnosis preoperatively. The operating room should be cleared of all unnecessary equipment, and staffing kept to minimum $[2,11]$. The patient should be scheduled last on the operating list where possible, to allow extended cleaning of room surfaces prior to its next use $[10,12]$. Staff must wear a disposable liquid-repellent gown over a plastic apron, gloves, mask and goggles or full-face visor for procedure [2,4]. These items should be used once only and destroyed by incineration. In asymptomatic at risk patients the above precautions also apply, but gowns may be reprocessed if not of single-use [4]. Invasive procedures, such as central venous cannulation and spinal anesthesia, mandate the use of full aseptic procedures including mask and eye protection [13].

Whenever possible, disposable anesthetic equipment should be used and incinerated afterward, which includes face-masks, oropharyngeal, nasal and laryngeal mask airway, laryngoscope, and tracheal tubes $[2,4,13]$. When non-single-use instruments are applied, they should be treated according to the patient's and the tissue risk [10]. High risk tissues for CJD are those in brain, spinal cord, and posterior eye, and medium risk tissues are those in the anterior eye, olfactory epithelium and in vCJD lymphoid tissue. Instruments exposed to procedure involving these tissues should be destroyed in cases of definite or probable CJD. In remaining group of patients (those with possible infectivity), instruments exposed to procedures involving high and medium risk tissues should be quarantined until a definite diagnosis has been confirmed. Quarantined instruments may be used again for the same patient during the course of their treatment $[4,13]$.

Farling and Smith [2] stated that ventilators must not be used again for other patients except those with a definitive diagnosis of CJD. In our case, we used Ambu-bags with TIVA, instead of anesthetic machines with vaporizers. However, this advice is not current. CJD Incidents Panel recommends that the anesthetic circuit should be disposed of, single-use filters should always be used and there is no requirement to quarantine the anesthetic machine [14]. It may be recommended to recover the patient in the operating room to avoid additional contamination.

CJD is a rare disease and sporadic CJD is the most common. However, anesthesiologists should be aware of the nature of
CJD and recommended precautions in handling of patients with CJD because it is potentially iatrogenically transmissible. This knowledge is necessary to provide optimal care for the patient and minimize the risk of transmission between hospital workers and patients.

\section{References}

1. Brown P, Gibbs CJ Jr, Rodgers-Johnson P, Asher DM, Sulima MP, Bacote A, et al. Human spongiform encephalopathy: the National Institutes of Health series of 300 cases of experimentally transmitted disease. Ann Neurol 1994; 35: 513-29.

2. Farling P, Smith G. Anaesthesia for patients with Creutzfeldt-Jakob disease. A practical guide. Anaesthesia 2003; 58: 627-9.

3. Zobeley E, Flechsig E, Corrizio A, Enari M, Weissmann C. Infectivity of scrapie prions bound to a stainless steel surface. Mol Med 1999; 5: 240-3.

4. Telefer M. Creutzfeldt-Jakob disease - implications for anaesthetists in New Zealand. Anaesth Intensive Care 2009; 37: 386-91.

5. Brown P, Preece MA, Will RG. "Friendly fire" in medicine: hormones, homografts, and Creutzfeldt-Jakob disease. Lancet 1992; 340: 24-7.

6. Duffy P, Wolf J, Collins G, DeVoe AG, Streeten B, Cowen D. Letter: Possible person-to-person transmission of Creutzfeldt-Jakob disease. N Engl J Med 1974; 290: 692-3.

7. Schoene WC, Masters CL, Gibbs CJ Jr, Gajdusek DC, Tyler HR, Moore FD, et al. Transmissible spongiform encephalopathy (CreutzfeldtJakob disease). Atypical clinical and pathological findings. Arch Neurol 1981; 38: 473-7.

8. Berger JR, David NJ. Creutzfeldt-Jakob disease in a physician: a review of the disorder in health care workers. Neurology 1993; 43: 205-6.

9. Will RG, Ironside JW, Zeidler M, Cousens SN, Estibeiro K, Alperovitch A, et al. A new variant of Creutzfeldt-Jakob disease in UK. Lancet 1996; 347: 921-5.

10. Ministry of Health. Guidance from the Advisory Committee on Dangerous Pathogens' Ministry of Health. Guidance from the Advisory Committee on Dangerous Pathogen's TSE working group Part 4. [2008 Nov] Available from http://www.advisorybodies.doh. gov.uk/acdp/tseguidance/Index.htm.

11. WHO manual for surveillance of human transmissible spongiform encephalopathies. [2008 Nov] Available from http://whqlibdoc. who.int/publications/2003/9241545887.pdf.

12. Australian Government Department of Health and Ageing. Infection Control Guidelines. Part 4-31. [2008 Nov] Available from http://www.health.gov.au/internet/main/publishing.nsf/Content/ icg-guidelines-index.htm.

13. Association of Anaesthetists of Great Britain and Ireland. Infection control in anaesthesia. Anaesthesia 2008; 63: 1027-36.

14. CJD Incidents Panel. Annual Report of the CJD Incidents Panel 2001-2002 (Jan 2003). [2008 Nov] Available from http://www.hpa. org.uk/web/HPAwebfile/HPAweb_C/1194947310873. 